\title{
Sorção de potássio em amostras de solo submetidas à aplicação de vinhaça
}

\author{
Lorena M. Nicochelli ${ }^{1}$, Rejane Nascentes ${ }^{2}$, \\ Eliana B. N. R. Lima ${ }^{3}$ \& Fernanda S. C. Soares ${ }^{2}$
}

\begin{abstract}
RESUMO
No processo de produção do etanol a vinhaça é um subproduto gerado em grande escala, em média, na razão de aproximadamente $13 \mathrm{~L}$ de vinhaça por litro de álcool destilado. Este volume produzido representa um problema no acondicionamento e nos processos de tratamento deste efluente que, na maioria das vezes, é lançado no solo por fertirrigação. Tendo em vista os altos teores de nutrientes, com destaque para o potássio e o alto teor de matéria orgânica, a disposição da vinhaça no solo necessita de estudos, uma vez que pode ocorrer lixiviação de vários desses elementos às águas subsuperficiais. Foram realizados ensaios de batelada, o que permitiu a avaliação do efeito de diferentes fatores, como a variação da razão solo: solução e do tempo de contato na sorção do potássio em três amostras de solo distintas, submetidas à aplicação de vinhaça. Nos ensaios com razão solo:solução 1:50; em todas as amostras, houve maior sorção que na razão 1:4. O tempo de contato ideal para estabelecimento das condições de equilíbrio foi $24 \mathrm{~h}$. Dentre as amostras estudadas a maior sorção foi constatada para a amostra com maior percentual de argila em sua composição e maior capacidade de troca catiônica.
\end{abstract}

Palavras-chave: ensaio de batelada, isoterma, resíduo agroindustrial

\section{Sorption of potassium in soil submitted to application of vinasse}

\begin{abstract}
In the process of producing ethanol, vinasse is a by-product generated in large scale, on average, at a rate around $13 \mathrm{~L}$ of vinasse per liter of distilled alcohol. This volume represents a problem in conditioning and treatment processes of this wastewater, which most of time is incorporated into the soil by fertigation. Considering the high levels of nutrients, especially potassium and the high content of organic matter, the disposal of vinasse into the soil needs further studies, because there may be leaching of several elements to groundwater. Batch tests were performed, which allowed assessment of the effect of different factors such as variation of the soil to solution ratio and the variation of contact time between soil and solution to evaluate the mobility of potassium in three different soil samples. The results showed that in the tests with the soil:solution ratio of 1:50, in all samples, the sorption was greater than with the ratio 1:4. The ideal contact time for establishment of equilibrium conditions was $24 \mathrm{~h}$. The sample with higher percentage of clay and higher cation exchange capacity demonstrated the highest sorption of potassium.
\end{abstract}

Key words: batch test, isotherm, agroindustrial residue

\footnotetext{
Mestre em Engenharia de Edificações e Ambiental, FAET/UFMT. Av. Fernando Correa da Costa s/n, CEP 78060-200, Cuiabá, MT. E-mail: Imnicochelli@hotmail.com

2 ICET/UFV - Campus de Rio Paranaíba, Rodovia MG-230 Km 7, CP 22, CEP 38810-000, Rio Paranaíba, MG. Fone: (34) 3855 9300. Email: rejane.nascentes@ufv.br; fernanda.santiago@ufv.br

ESAMB/UFMT, Av. Fernando Correa da Costa s/n, CEP 78060-200, Cuiabá, MT. Fone (65) 3615 8722. E-mail: elianar@ufmt.br
} 


\section{INTRODUÇÃO}

No processo de produção do etanol a vinhaça é um subproduto gerado em grande escala, em média, na razão de 10 a 15 L de vinhaça por litro de álcool destilado (Cruz et al., 2008). É um resíduo de natureza ácida, que atinge altas temperaturas ao sair do destilador e caracterizado por apresentar elevados índices de matéria orgânica (Salomon \& Lora, 2005). A grande geração representa um problema no acondicionamento e nos processos de tratamento deste efluente.

A literatura é unânime ao afirmar que o destino final da vinhaça até meados da década de 70, eram os corpos d'água, causando grande poluição e mortandade de peixes (Gonçalves, 2005). Esta forma de disposição se intensificou ainda mais a partir da criação do Proálcool, pelo incremento na produção do álcool e consequente aumento do volume de vinhaça.

Diante disto, as indústrias buscaram novas alternativas de disposição e a vinhaça, antes lançada in natura nos corpos d'água, passou a ser lançada no solo, na maioria das vezes por fertirrigação, significando uma forma de disposição de baixo custo, por não requerer grandes investimentos e uso de tecnologia e ainda aproveitar o potencial de fertilização do solo (Canellas et al., 2003).

Tendo em vista os altos teores de nutrientes, como potássio, cálcio e magnésio e, principalmente, de matéria orgânica, a disposição da vinhaça no solo como fertilizante, não deve ultrapassar, quando aplicada em grandes quantidades, a capacidade de retenção de água do solo (Silva et al., 2007), uma vez que pode ocorrer lixiviação de vários desses elementos, sobremaneira do potássio, presente em grande quantidade nesse resíduo, com a possibilidade de alcançar as águas subsuperficiais.

Ante o exposto e em virtude do crescente uso da vinhaça como fonte de nutrientes e da escassez de informações sobre seu potencial contaminante ao solo e aos recursos hídricos em geral objetivou-se, através deste trabalho, avaliar a sorção do potássio e o efeito da variação da razão solo:solução e do tempo de contato na mobilidade do potássio em amostras de solo, sedimento e material de empréstimo da região de Jaciara, MT.

\section{Material e MÉTODOS}

O trabalho de campo foi realizado na Usina Pantanal de Açúcar e Álcool Ltda, localizada no município de Jaciara, coordenadas $15^{\circ} 55^{\prime} 30^{\prime \prime} \mathrm{S}$ e $55^{\circ} 13^{\prime} 34^{\prime \prime} \mathrm{W}$, rodovia BR $364, \mathrm{~km}$ 289,1 . A região é caracterizada por clima tropical quente e subúmido, com quatro meses de seca, de maio a agosto e precipitação anual de $1.750 \mathrm{~mm}$, com intensidade máxima em dezembro, janeiro e fevereiro.

Amostras de sedimento foram coletadas dentro de um dos tanques de armazenamento de vinhaça e água de lavagem (Amostra 1), material de empréstimo na passarela entre as lagoas, isto é, na parte superior de um dos taludes entre as lagoas (Amostra 2) e no horizonte superficial do solo agricultável, rente à plantação de cana-de-açúcar, é feita, anualmente, aplicação de vinhaça para a fertirrigação (Amostra 3). As amostras foram submetidas aos ensaios de caracterização geotécnica, química e mineralógica. Também foi feita a coleta de vinhaça pura na saída dos destiladores e determinadas suas características físico-químicas.

Os ensaios de batelada - batch test (USEPA, 1992) foram conduzidos no Laboratório de Física do Solo e as análises realizadas no Laboratório de Físico-Química, da UFMT, entre julho e outubro de 2010.

A proposta adotada neste trabalho foi avaliar a sorção do potássio contido na vinhaça nas amostras coletadas e considerar os efeitos da variação da razão solo:solução e da variação do tempo de contato entre o solo e a solução. Du et al. (2004) e Sartaj \& Fernandes (2005) trabalharam com sorção de potássio e boro, respectivamente, e investigaram o efeito de vários fatores no processo de sorção, dentre eles o tempo de contato e a razão solo:solução.

Para cada amostra foram realizados ensaios com duas razões solo:solução, 1:4 e 1:50. Para os ensaios com razão 1:4, a quantidade utilizada de solo seco foi $7 \mathrm{~g}$ e o volume de solução de $28 \mathrm{~mL}$, para a razão 1:50 a massa de solo foi 0,7 $\mathrm{g}$ e o volume de solução de $35 \mathrm{~mL}$.

Os ensaios foram realizados com 10 concentrações para o potássio em que a primeira solução era a vinhaça bruta com teor $1700 \mathrm{mg} \mathrm{L}^{-1}$ de potássio e, a partir deste valor a amostra foi diluída.

Para cada solução foram realizadas três repetições e um branco. Utilizaram-se tubos de centrífuga de capacidade de 50 $\mathrm{mL}$, com tampa e nos tempos de agitação de 6 e $24 \mathrm{~h}$, em um agitador horizontal, na rotação de $100 \mathrm{rpm}$, sob temperatura ambiente. Decorrido o tempo de agitação a etapa posterior foi a centrifugação das amostras numa centrífuga a $3000 \mathrm{rpm}$ por 10 min; após a centrifugação o sobrenadante foi filtrado a vácuo e acondicionado em frasco plástico e só então mantido resfriado até a leitura do potássio em fotometria de chama.

\section{RESULTADOS E DISCUSSÃO}

\section{Caracterização das amostras de materiais}

As curvas granulométricas para as amostras estão apresentadas na Figura 1.

A classe textural das amostras foi obtida de acordo com a classificação do Sistema Unificado de Classificação de Solos (USCS), descrita pela norma D2487 da American Society for

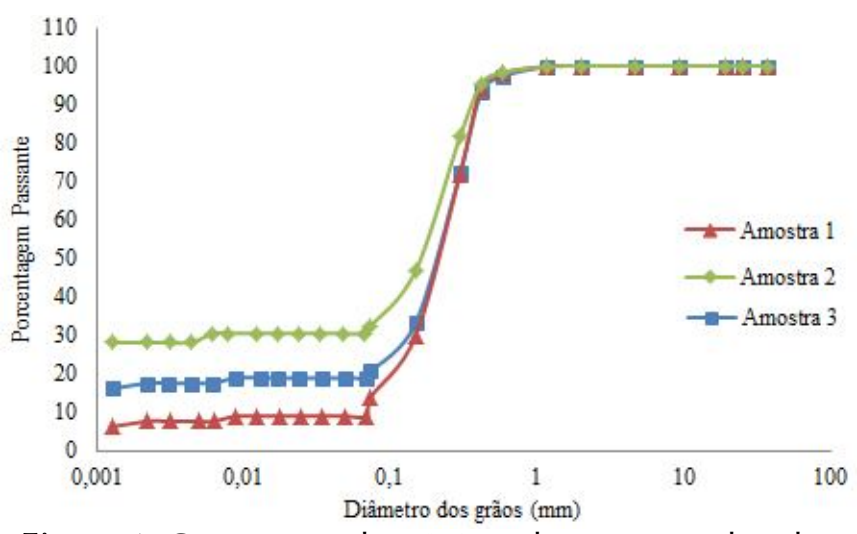

Figura 1. Curvas granulométricas das amostras de solos 
Tabela 1. Caracterização química das amostras estudadas

\begin{tabular}{ccccccccrccc}
\hline Amostras & $\mathbf{p H}$ & $\mathbf{P}$ & $\mathbf{K}$ & $\mathbf{C a}$ & $\mathbf{M g}$ & $\mathbf{A l}$ & $\mathbf{H}$ & Mat. Org. & S & CTC & V (\%) \\
1 & 3,7 & 51,7 & 8 & 0,8 & 0,2 & 0,9 & 2,3 & 21,3 & 1,0 & 4,2 & 24,3 \\
2 & 5,2 & 1,7 & 40 & 2,3 & 0,7 & 0,0 & 2,3 & 8,7 & 3,1 & 5,4 & 57,2 \\
3 & 5,2 & 5,6 & 26 & 1,5 & 0,5 & 0,0 & 1,9 & 12,8 & 2,1 & 4,0 & 51,9 \\
\hline
\end{tabular}

$\mathrm{P}$ e K em mg dm${ }^{-3}, \mathrm{Ca}+\mathrm{Mg}, \mathrm{Ca}, \mathrm{Mg}, \mathrm{Al}$ e $\mathrm{H} \mathrm{em} \mathrm{cmol}_{\mathrm{c}} \mathrm{dm}^{-3}$ e matéria orgânica em g dm${ }^{-3}$

$\mathrm{S}$ - soma de bases em $\mathrm{cmol}_{\mathrm{c}} \mathrm{dm}^{-3}$

CTC - capacidade de troca catiônica em $\mathrm{cmol}_{\mathrm{c}} \mathrm{dm}^{-3}$

$\mathrm{V}$ - Saturação por bases

Sat. Al: $m \%=A l+(A l+S) 100$

Testing Materials (ASTM, 1993). A Amostra 2 foi classificada como areia argilosa e as Amostras 1 e 3 como SP - areia malgraduada.

Os valores obtidos pelos ensaios de caracterização evidenciam que as três amostras são arenosas e entre elas a Amostra 2 foi a que apresentou maior teor de argila, em torno de $28 \%$; por sua vez, a Amostra 1 possui o maior teor de areia, acima de $90 \%$ e a Amostra $3, \operatorname{com} 81 \%$ de areia.

Os valores de massa específica dos sólidos para as três amostras são $g_{s}=2,624$ (Amostra 1), 2,558 (Amostra 2) e 2,551 (Amostra 3$) \mathrm{g} \mathrm{cm}^{-3}$.

Os resultados da caracterização química das três amostras são descritos na Tabela 1 .

A caracterização físico-química da vinhaça não foi diferente do que é apresentado na literatura, conforme os trabalhos de Lyra et al. (2003) e Brito et al. (2005), uma vez que apresentou baixo $\mathrm{pH}$ e elevados valores de DBO e DQO, em razão do grande conteúdo de matéria orgânica. Shenbagavalli \& Mahimairaja (2009) ressaltam a acidez do efluente, $\mathrm{pH}<4,0$ e os altos níveis de sais solúveis, principalmente o potássio, nitrogênio e fósforo.

Comumente presentes na vinhaça, apenas variando suas quantidades conforme a origem do mosto, o cálcio, o magnésio e o potássio foram detectados em níveis consideráveis, com destaque para o potássio. Os valores estão apresentados na Tabela 2.

\section{Ensaio de sorção - ensaio de batelada}

As isotermas de sorção nos modelos de Freundlich e Langmuir, para as amostras 1, 2 e 3, estão apresentadas nas Figuras 2, 3 e 4; os parâmetros das equações de Feundlich e Langmuir são descritos na Tabela 3.

As isotermas de Freundlich e de Langmuir para as três amostras obtiveram bom ajuste, conforme os valores de $\mathrm{R}^{2} \mathrm{e}$ as isotermas apresentadas. Os valores de $\mathrm{R}^{2}$ para o modelo de
Tabela 2. Características físico-químicas da vinhaça

\begin{tabular}{|c|c|}
\hline Parâmetros & Valores \\
\hline $\mathrm{pH}$ a $25^{\circ} \mathrm{C}$ & 3,6 \\
\hline Sólidos Totais $\left(\mathrm{mg} \mathrm{L}^{-1}\right)$ & 57152,0 \\
\hline Sólidos Totais Fixos $\left(\mathrm{mg} \mathrm{L}^{-1}\right)$ & 38604,0 \\
\hline Sólidos Totais Voláteis $\left(\mathrm{mg} \mathrm{L}^{-1}\right)$ & 18548,0 \\
\hline Nitrato $\left(\mathrm{mg} \mathrm{L}^{-1}\right)$ & 0,1 \\
\hline Nitrogênio Amoniacal (mg L-1) & 252,0 \\
\hline $\mathrm{DBO}\left(\mathrm{mg} \mathrm{L}^{-1}\right)$ & 19591,2 \\
\hline $\mathrm{DQO}\left(\mathrm{mg} \mathrm{L}^{-1}\right)$ & 55680,0 \\
\hline Potássio (mg L-1) & 1700,0 \\
\hline Carbono orgânico $\left(\mathrm{g} \mathrm{L}^{-1}\right)$ & 8,1 \\
\hline Cálcio (mg L-1) & 140,0 \\
\hline Magnésio $\left(\mathrm{mg} \mathrm{L}^{-1}\right)$ & 110,0 \\
\hline Sulfeto $\left(\mathrm{mg} \mathrm{L}^{-1}\right)$ & 42,6 \\
\hline Fósforo total (mg L-1) & 34.4 \\
\hline
\end{tabular}

Freundlich, razão 1:4, variaram de 0,9522 a 0,9844 e razão 1:50, 0,9147 a 0,9822 . Para Langmuir, $R^{2}$, razão 1:4, variou de 0,8433 a 0,992 e $1: 50$, de 0,929 a 0,9919 .

Ressalta-se que o modelo de Freundlich supõe sorção ilimitada, isto é, o solo nunca é saturado para atingir sua capacidade de retenção (Yamamura, 2009), porque o número de sítios de adsorção é muito maior do que a quantidade de moléculas de soluto e a isoterma não exibe um patamar de concentração máxima. Foi o que ocorreu com as isotermas de Freundlich, Figuras 2A,B, 3A,B, e 4A, B, que demonstram tendência de crescimento não constante dos pontos.

Na teoria de Langmuir tem-se a hipótese de que a sorção se restringe a uma única camada de moléculas da substância sobre a superfície das partículas sólidas, a sorção aumenta linearmente com o aumento da concentração de soluto e se aproxima de um valor constante, devido ao limitado número de sítios de sorção (Gonçalves, 2006). Neste modelo a relação entre a concentração da substância sorvida e a concentração

Tabela 3. Parâmetros de sorção dos modelos de Freundlich e Langmuir

\begin{tabular}{|c|c|c|c|c|c|c|c|c|}
\hline \multirow{2}{*}{ Amostras } & \multirow{2}{*}{$\begin{array}{c}\text { Razão } \\
\text { solo:solução }\end{array}$} & \multirow{2}{*}{$\begin{array}{l}\text { Tempo de } \\
\text { contato (h) }\end{array}$} & \multicolumn{3}{|c|}{ Parâmetros de Freundlich } & \multicolumn{3}{|c|}{ Parâmetros de Langmuir } \\
\hline & & & $\varepsilon$ & $\mathrm{K}_{\mathrm{F}}$ & $\mathbf{R}^{2}$ & $\mathrm{~S}_{\mathrm{m}}$ & b & $\mathbf{R}^{2}$ \\
\hline \multirow{4}{*}{ Amostra 1} & \multirow{2}{*}{$1: 4$} & 24 & 0,4519 & 0,011013 & 0,9698 & 0,3746 & 0,0019 & 0,8483 \\
\hline & & 6 & 0,7457 & 0,000682 & 0,9706 & 0,5495 & 0,0003 & 0,9920 \\
\hline & \multirow{2}{*}{$1: 50$} & 24 & 0,5804 & 0,096607 & 0,9147 & 13,5318 & 0,0007 & 0,9685 \\
\hline & & 6 & 0,4425 & 0,202402 & 0,9776 & 7,1124 & 0,0017 & 0,9426 \\
\hline \multirow{4}{*}{ Amostra 2} & \multirow{2}{*}{$1: 4$} & 24 & 0,5127 & 0,024012 & 0,9672 & 0,9856 & 0,0029 & 0,9041 \\
\hline & & 6 & 0,7545 & 0,002052 & 0,9844 & 0,7113 & 0,0010 & 0,9272 \\
\hline & \multirow[b]{2}{*}{$1: 50$} & 24 & 0,5684 & 0,200649 & 0,9804 & 12,2249 & 0,0033 & 0,9290 \\
\hline & & 6 & 0,5823 & 0,157867 & 0,9822 & 17,4216 & 0,0010 & 0,9919 \\
\hline \multirow{4}{*}{ Amostra 3} & \multirow[b]{2}{*}{$1: 4$} & 24 & 0,6237 & 0,011625 & 0,9756 & 1,0148 & 0,0031 & 0,9829 \\
\hline & & 6 & 0,4461 & 0,018849 & 0,9522 & 0,5075 & 0.0033 & 0,9372 \\
\hline & \multirow[b]{2}{*}{$1: 50$} & 24 & 0,3393 & 0,879502 & 0,9456 & 9,4787 & 0,0103 & 0,9853 \\
\hline & & 6 & 0,1888 & 1,352156 & 0,9296 & 5,7737 & 0,0068 & 0,9353 \\
\hline
\end{tabular}



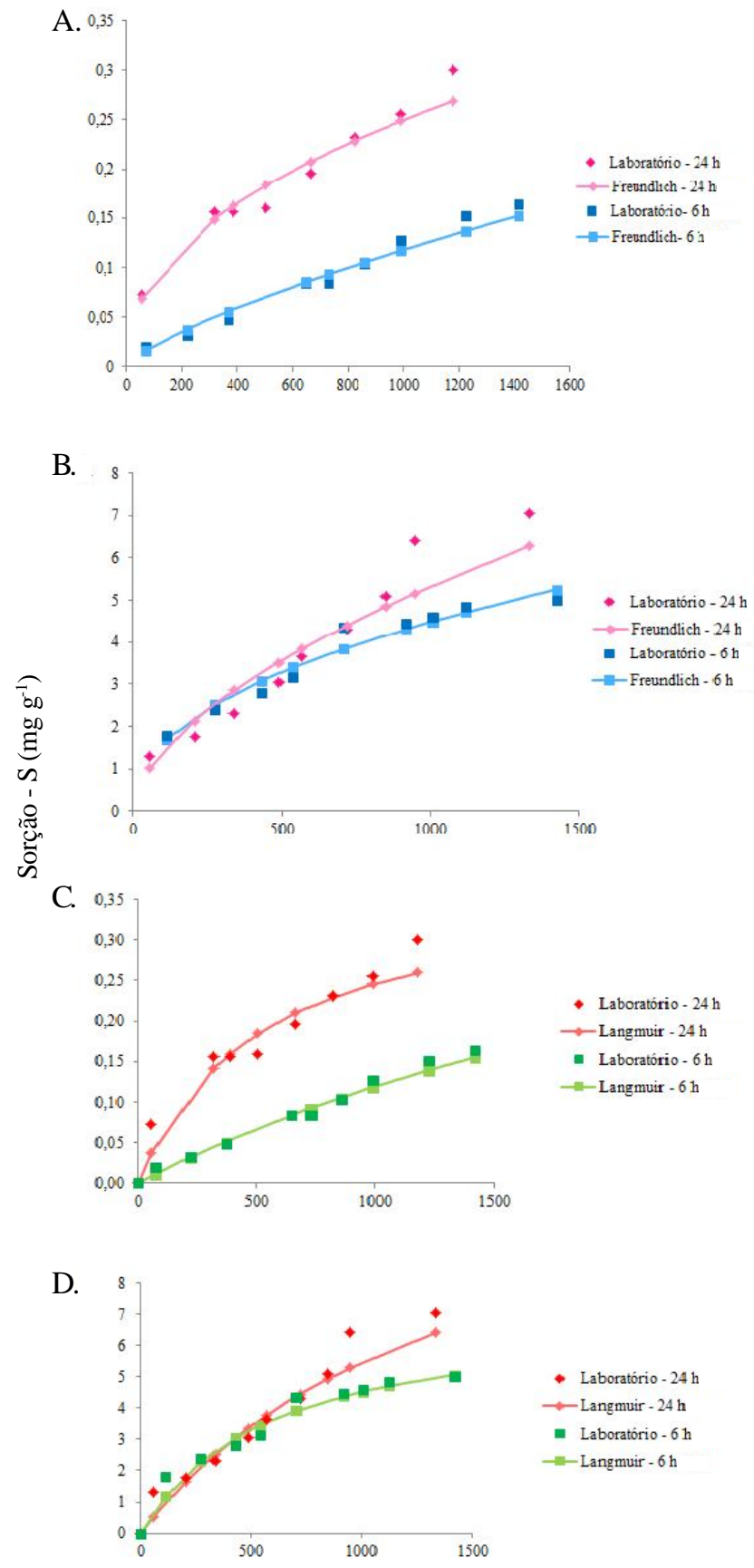

Concentração de Equilíbrio - CE (mg L $\left.{ }^{-1}\right)$

Figura 2. Isotermas de sorção (A) Freundlich para a amostra 1, razão 1:4 (B) Freundlich para a amostra 1, razão 1:50 (C) Langmuir para a amostra 1, razão 1:4 (D) Langmuir para a amostra 1, razão 1:50

de equilíbrio da mesma na solução é baseada no equilíbrio estabelecido entre as velocidades de sorção e de dessorção. Nas isotermas de Langmuir (Figuras 2C,D, 3C,D, 4C,D) é possível perceber a tendência de formação de um patamar definido nas curvas confirmando que o modelo é ideal para solos que atinjam a sorção máxima. Foi observado que a variação no tempo de contato provocou efeitos no processo de sorção. Para as três amostras, em todos os ensaios realizados com tempo de contato de $24 \mathrm{~h}$ houve maior sorção do potássio. O tempo de $24 \mathrm{~h}$, intervalo comumente utilizado, foi adequado
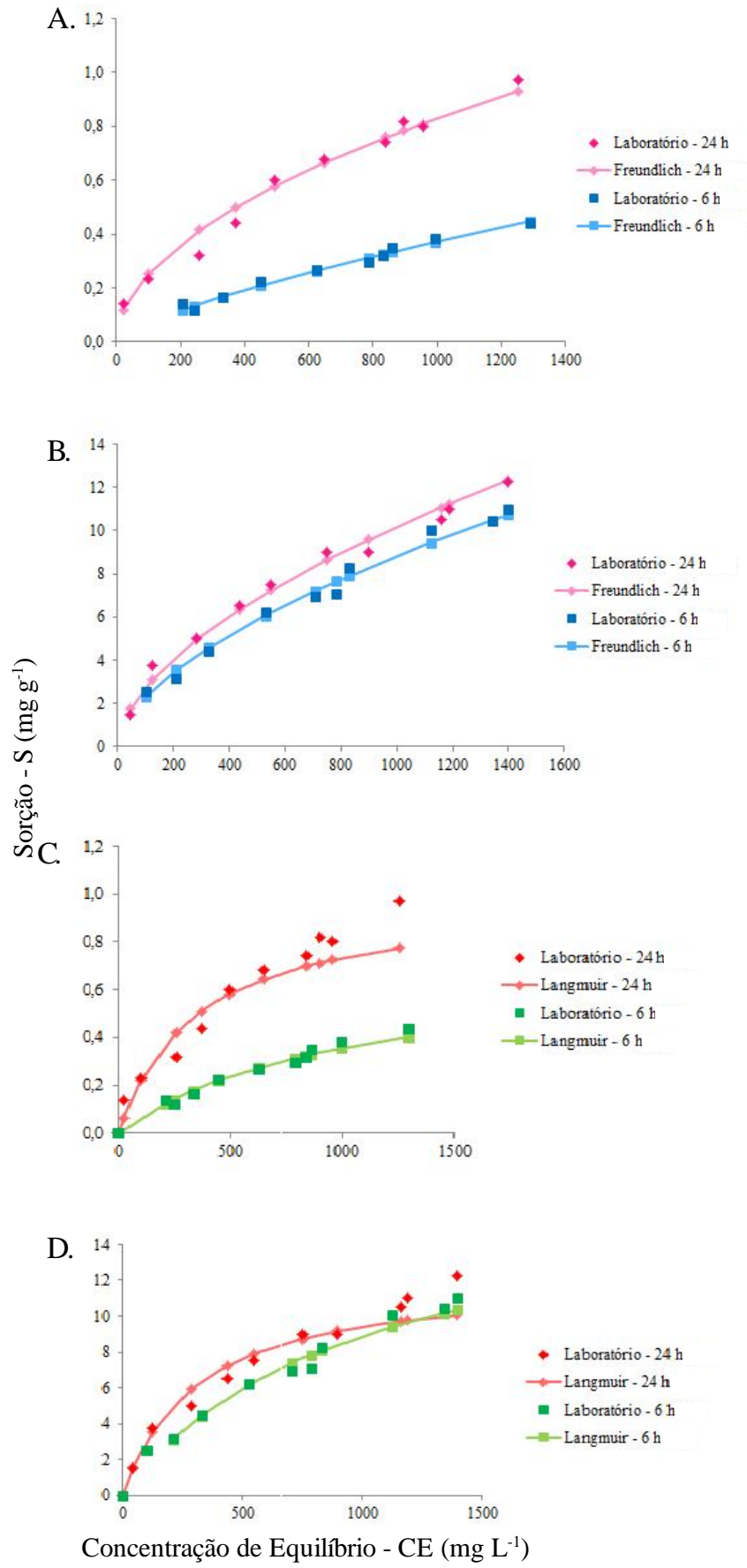

Figura 3. Isotermas de sorção (A) Freundlich para a amostra 2, razão 1:4 (B) Freundlich para a amostra 2, razão 1:50 (C) Langmuir para a amostra 2, razão 1:4 (D) Langmuir para a amostra 2, razão 1:50

para o estabelecimento das condições de equilíbrio e está de acordo com recomendações da USEPA (1992), sendo o tempo de $6 \mathrm{~h}$ insuficiente para estabelecer o equilíbrio. Esta norma sugere que o tempo de equilíbrio deve ser o mínimo necessário para estabelecer uma taxa de variação da concentração do soluto em solução, igual ou menor que $5 \%$ por um intervalo de $24 \mathrm{~h}$.

Santos et al. (2006) observou, trabalhando com sorção de potássio em material caulinítico, nos tempos de 1,24, 48 e $72 \mathrm{~h}$, que o tempo de estabilização do $\mathrm{K}^{+}$foi de $24 \mathrm{~h}$. Por outro lado, 

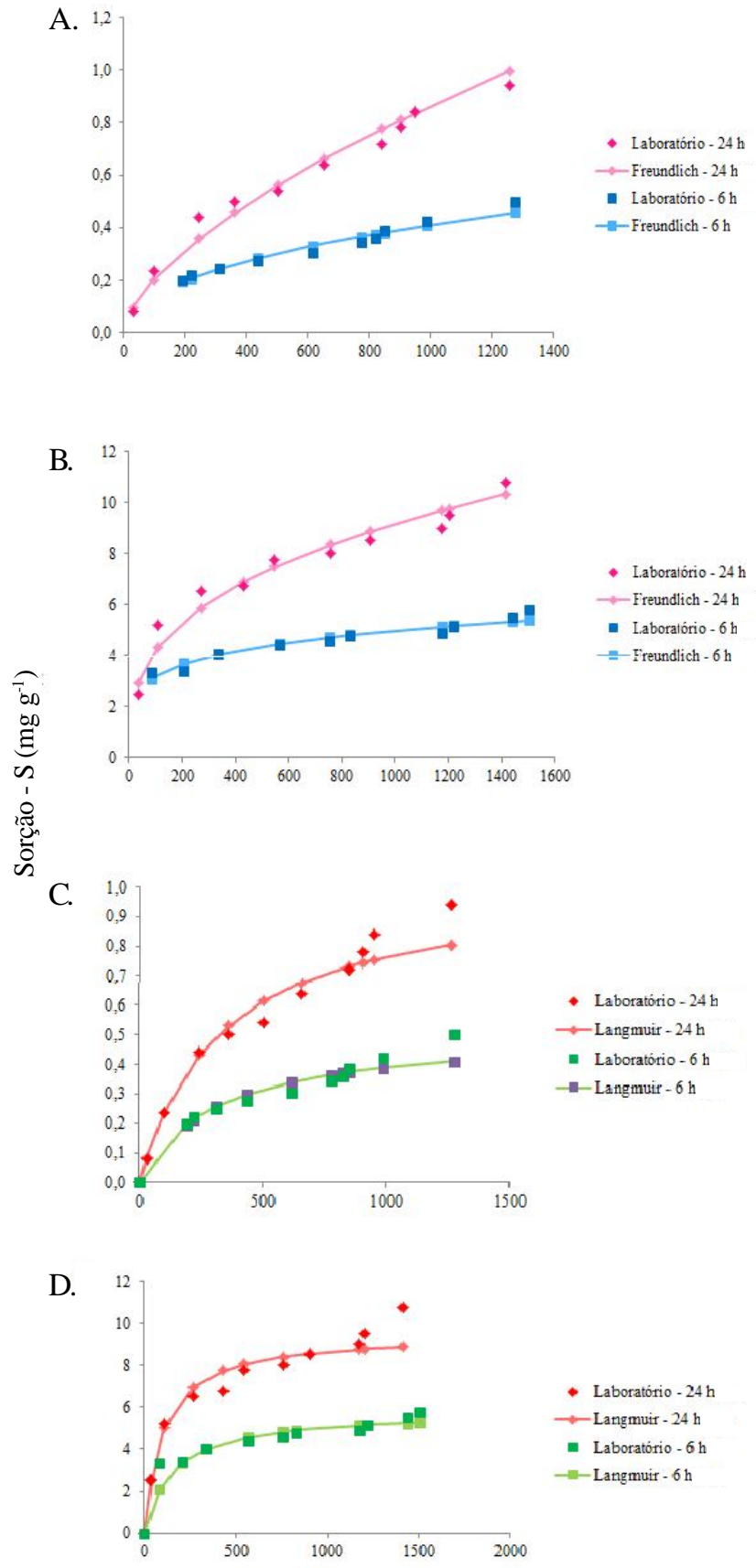

Concentração de Equilíbrio - CE (mg L $\left.{ }^{-1}\right)$

Figura 4. Isotermas de sorção (A) Freundlich para a amostra 3, razão 1:4 (B) Freundlich para a amostra 3, razão 1:50 (C) Langmuir para a amostra 3, razão 1:4 (D) Langmuir para a amostra 3, razão 1:50

Mellis \& Rodella (2008) concluíram, avaliando o efeito dos tempos de agitação de 1 e $24 \mathrm{~h}$ no equilíbrio de adsorção de metais em solo natural e tratado com lodo de esgoto, que o tempo de agitação de 24 h é o mais adequado para obtenção da adsorção dos metais estudados. Os autores ainda afirmaram que na maioria dos trabalhos de adsorção em solos tropicais publicados se constata que se tem utilizado o tempo de agitação de $24 \mathrm{~h}$, entre eles Dias et al. (2001); Silveira \& Alleoni (2003); Casagrande et al. (2004); Mellis et al. (2004); Soares (2004); Alleoni et al. (2005) e Vega et al. (2006).
Na variação da razão solo:solução ficou patente que os ensaios com razão 1:50 tiveram maior sorção que os ensaios com razão 1:4, porque uma razão menor proporciona maior área superficial e mais sítios disponíveis (Du et al., 2004), possibilitando maior troca (sorção) entre as partículas de solo e o potássio. A mesma tendência foi constatada por Du et al. (2004), ao avaliarem a sorção do potássio com as razões 1:20, 1:10 e 1:4, trabalhando com solos argilosos, em que a quantidade sorvida diminuiu com o aumento da razão solo:solução. Chang et al. (2002) também concluíram, pesquisando a adsorção de $\mathrm{Cu}^{2+} \mathrm{em}$ solo laterítico com razões variando de 0,1 a $2 \mathrm{~g} \mathrm{~mL}^{-1}$, que a quantidade adsorvida diminuiu com o aumento da razão solo:solução.

Constatou-se que os menores valores de sorção foram encontrados nos ensaios com a Amostra 1, tanto nas razões $1: 4 \mathrm{e} 1: 50$ como nos tempos de $24 \mathrm{e} 6 \mathrm{~h}$. $\mathrm{O}$ valor de $\mathrm{pH} \mathrm{em} \mathrm{CaCl}_{2}$ encontrado foi 3,7, o mais baixo entre as amostras estudadas. A característica ácida da amostra pode ter influenciado no processo de sorção, tendo em vista que as soluções ácidas tendem a dificultar mais as trocas catiônicas do que as soluções alcalinas pelo fato de que há competição entre cátions e o $\mathrm{H}^{+}$ nos sítios de sorção.

A baixa sorção para a Amostra 1 também pode relacionar-se com o elevado percentual de areia em sua composição, acima de $90 \%$. O mesmo foi observado por Lelis Neto (2008), que trabalhou com o Latossolo Vermelho, fase arenosa, e o Nitossolo, e verificou que o íon potássio apresentou no solo argiloso maior interação com a fração sólida que no solo arenoso, visto que houve um carreamento de potássio para a profundidade no solo arenoso.

Ainda segundo Santos et al. (2006), que pesquisaram a adsorção de cloreto e potássio em solos tropicais, caulinita e laterita, concluíram que o material caulinítico adsorveu uma quantidade maior de potássio do que a amostra de solo laterítico, fato este explicado pela maior capacidade de troca catiônica e pela predominância de cargas superficiais negativas do material caulinítico.

Constatou-se que a Amostra 2 proporcionou a maior sorção entre as amostras, o que pode ser atribuído ao percentual de argila, em torno de 30\%, o maior entre as amostras. Conforme Queiroz (2002), como as argilas apresentam maior capacidade de troca iônica e, consequentemente, maior também será a sorção, sobretudo de cátions; a Amostra 2 é também a amostra com maior valor de CTC, em especial por possuir maior quantidade de argila, que tem carga negativa na superfície de suas partículas, favorecendo a troca de cátions, fator sumamente relevante na retenção do cátion potássio $\left(\mathrm{K}^{+}\right)$, que se apresenta em maior quantidade nesta amostra.

Bueno et al. (2009) concluíram, pesquisando o impacto causado pela adição de vinhaça nas propriedades de dois solos, um de textura arenosa e outro de textura argilosa (Vertissolo), que o Vertissolo tem maior capacidade de retenção da concentração salina introduzida pela aplicação da vinhaça, devido ao alto teor de argila; os autores afirmam, ainda, que o aumento na salinidade pode afetar algumas propriedades biológicas e bioquímicas dos solos.

A Amostra 3 apresentou resposta semelhante à Amostra 2, diferindo nos ensaios com razão 1:50, com S $=10 \mathrm{mg} \mathrm{g}^{-1}$ para 24 
$\mathrm{h}$ e $\mathrm{S}=6 \mathrm{mg} \mathrm{g}^{-1}$ para $6 \mathrm{~h}$, evento que pode ser relacionado à menor porcentagem de argila, $17,5 \%$ e, consequentemente, menos sítios disponíveis para sorção.

Goudar (2006) concluiu, avaliando a dinâmica do potássio em um Vertissolo irrigado com vinhaça, que houve acúmulo de $\mathrm{K}$ no solo, percentual que aumentou com a profundidade em todos os solos e, segundo o autor, isto é devido principalmente ao elevado teor de $\mathrm{K}$ na vinhaça e à lixiviação durante a irrigação. O autor afirma que, em geral, o k trocável aumentou em profundidade na maioria dos solos e seguiu o padrão de distribuição de argila com a profundidade. Os valores relativamente mais elevados de $\mathrm{k}$ na subsuperficie podem ser relacionados com o efeito da lixiviação. Constatou-se maior adsorção do potássio em solos irrigados com vinhaça do que no solo não irrigado e, dentre os solos irrigados, maior adsorção nos solos com mais de 20 anos de irrigação e menor adsorção no solo com 5 a 10 anos de irrigação. Bhat (1994) também verificou, investigando o efeito da vinhaça nas propriedades do solo, aumento nos teores de potássio, com a profundidade.

\section{ConclusõEs}

1. O processo de sorção é dependente do tempo de contato entre o solo e a solução; para tanto, a melhor sorção para todas as amostras, tanto com razão 1:4 como com razão 1:50, ocorreu com $24 \mathrm{~h}$; notou-se que o tempo de $6 \mathrm{~h}$ é insuficiente para estabelecer o equilíbrio.

2. Constatou-se que a variação da razão solo:solução produz efeitos na quantidade sorvida; de fato, a menor razão solo:solução, 1:50, proporcionou maiores valores de sorção para o potássio.

3. $\mathrm{O}$ íon potássio teve maior afinidade com a amostra com maior percentual de argila e maior CTC.

4. Houve pouca sorção para as amostras de sedimento cuja composição é predominantemente arenosa.

\section{LITERATURA CITADA}

Alleoni, L. R. F.; Iglesias, C. S. M.; Mello, S. C.; Camargo, O. A.; Casagrande, J. C.; Lavorenti, N. A. Atributos do solo relacionados à adsorção de cádmio e cobre em solos tropicais. Acta Scientarum Agronomica, v.27, p.729-737, 2005.

ASTM - American Society for Testing and Materials. Standard classification of soils for engineering purposes. ASTM D 2487. West Conshohocken, 1993.11p.

Bhat, S. N. Investigation of effect of lagoon spentwash on soil properties. Dharwad: UAS, 1994. 295p. Dissertação Mestrado

Brito, F. L.; Rolim, M. M.; Pedrosa, E. M. R. Teores de potássio e sódio no lixiviado e em solos após a aplicação de vinhaça. Revista Brasileira de Engenharia Agrícola e Ambiental, v.9, p.52-56, 2005.

Bueno, P. C.; Rubí, J. A. M.; Giménez, R. G.; Ballesta, R. J. Impacts caused by the addition of wine vinasse on some chemical and mineralogical properties of a Luvisol and a Vertisol in La Mancha (Central Spain). Journal Soil Sediments, v.9, p.121-128, 2009.
Canellas, L. P.; Velloso, A. C. X.; Marciano, C. R.; Ramalho, J. F. G. P.; Rumjanek, V. M.; Rezende, C. E.; Santos, G. A. Propriedades químicas de um Cambissolo cultivado com cana-de-açúcar, com preservação do palhiço e adição de vinhaça por longo tempo. Revista Brasileira de Ciência do Solo, v.27, p.935-944, 2003.

Casagrande, J. C.; Jordão, C. B.; Alleoni, L. R. F; Camargo, O. A. Copper desorption in a variable eletrical charge soil. Scientia Agricola, v.61, p.196-202, 2004.

Chang, T. W.; Wang, M. K.; Lin, C. Adsorption of copper in the different sorbent/water ratios of soil systems. Water, Air and Soil Pollution, v.138, p.199-209, 2002.

Cruz, J. I.; Portugal, R. S.; Lucendo, M. C. H.; Elis, V. R.; Fachin, S. J. S.; Ustra, A. T.; Borges, W. R. Detecção de contaminação de solo por vinhaça através de análise de dados de eletrorresistividade. Revista Brasileira de Geofísica, v.26, p.481-492, 2008.

Dias, N. M. P.; Alleoni, L. R. F., Casagrande, J. C.; Camargo, O. A. Adsorção de cádmio em dois Latossolos ácricos e um Nitossolo. Revista Brasileira de Ciência do Solo, v.25, p.297304, 2001.

Du, Y. J.; Hayashi, S.; Xu, Y. F. Some factors controlling the adsorption of potassium ions on clayey soils. Applied Clay Science, v.27, p.209-213, 2004.

Gonçalves, C. R. Remoção de manganês e recuperação de urânio presentes em águas ácidas de mina. Belo Horizonte: CNEN, 2006. 87p. Dissertação Mestrado

Gonçalves, D. B. Mar de cana, deserto verde? Dilemas do desenvolvimento sustentável na produção canavieira paulista. São Carlos: UFSCAR, 2005. 259p. Tese Doutorado

Goudar, M. S. Pottassium dynamics in spentwash irrigated Vertisol. Dharwad: UAS, 2006.104p. Dissertação Mestrado

Lelis Neto, J. A. Monitoramento dos componentes químicos da vinhaça aplicados em diferentes tipos de solo. São Paulo: USP, 2008. 89p. Dissertação Mestrado

Lyra, M. R. C. C.; Rolim, M. M.; Silva, J. A. A. Topossequência de solos fertigados com vinhaça: contribuição para a qualidade das águas do lençol freático. Revista Brasileira de Engenharia Agrícola e Ambiental, v.7, p.525-532, 2003.

Mellis, E. V.; Cruz, M. C. P.; Casagrande, J. C. Nickel adsoption by soils in relation to $\mathrm{pH}$, organic matter and iron oxides. Scientia Agricola, v.61, p.190-195, 2004.

Mellis, E. V.; Rodella, A. A. Influência do tempo de agitação na adsorção de $\mathrm{Cd}, \mathrm{Cu}$, Ni e Zn em latossolo tratado com lodo de esgoto. Revista Bragantia, v.67, p.977-982, 2008.

Queiroz, P. I. B. Um método numérico para análise de adensamento e transporte de contaminantes no solo. São José dos Campos: ITA, 2002.166 p. Tese Doutorado

Salomon, K. R; Lora, E. E. S. Estimativa do potencial de geração de energia elétrica para diferentes fontes de biogás no Brasil. Biomassa e Energia, v.2, p.57-67, 2005.

Santos, L. V.; Polivanov, H.; Alamino, R. C. J.; Silva, V. H. G. Adsorção de cloreto e potássio em solos tropicais. Anuário do Instituto de Geociências - UFRJ, v.29, p.101-121, 2006. 
Sartaj, M.; Fernandes, L. Adsorption of boron from landfill leachate by peat and the effect of environmental factors. Journal of Environmental Engineering and Science, v.4, p.19-28, 2005.

Shenbagavalli, S.; Mahimairaja, S. Agricultural use of distillery spentwash and its environmental impact. Pollution Research, v.28, p.367-382, 2009.

Silva, M. A. S., Griebeler, N. P., Borges, L. C. Uso de vinhaça e impactos nas propriedades do solo e lençol freático. Revista Brasileira de Engenharia Agrícola e Ambiental, v.11, p.108$114,2007$.

Silveira, M. L. A.; Alleoni, L. R. F. Copper adsorption in tropical Oxisols. Brazilian Archives of Biology and Technology, v.46, p.529-536, 2003.
Soares, M. R. Coeficiente de distribuição (KD) de metais pesados em solos do Estado de São Paulo. São Paulo: USP, 2004. 202p. Tese Doutorado

USEPA - United States Environmental Protection Agency Batch - type procedures for estimating soil adsorption of chemicals. EPA/530/SW-87/006-F. 1992, 101p.

Vega, F. A.; Covelo, E. F.; Andrade, M. L. Competitive sorption and desorption of heavy metals in mine soils: Influence of mine soil characteristics. Journal of Colloid and Interface Science, v.298, p.582-592, 2006.

Yamamura, A. P. G. Aplicação de nanotecnologia no meio ambiente: Biossorvente magnético na remoção de urânio. São Paulo: IPEN, 2009. 124p. Dissertação Mestrado 